\title{
ANALISIS USAHATANI SAYURAN SELADA MENGGUNAKAN HIDROPONIK SEDERHANA PADA LAHAN PEKARANGAN
}

\section{ANALYSIS OF LETTUCE FARMING USING SIMPLE HYDROPONIC IN YARD}

\author{
Anugerah Fitri Amalia* ${ }^{1}$, Annisa Fitri ${ }^{2}$, A. Dalapati ${ }^{1}$, Femmi Nor Fahmi ${ }^{1}$ \\ ${ }^{1}$ BPTP Sulawesi Tengah, Sulawesi Tengah, Indonesia \\ ${ }^{2}$ Program Studi Agribisnis Pangan Politeknik Negeri Lampung \\ *E-mail: anugerahamalia808@gmail.com \\ (Diterima 05-06-2020; Disetujui 06-07-2020)
}

\begin{abstract}
ABSTRAK
Peningkatan jumlah penduduk mengakibatkan banyak lahan pertanian yang beralih fungsi sebagai pemukiman, sehingga upaya pemenuhan pangan dari sektor pertanian tantangannya semakin meningkat. Salah satu upaya mengoptimalkan pemenuhan kebutuhan pangan dari lahan yang semakin sempit adalah memanfaatkan lahan pekarangan dengan pertanaman sistem hidroponik. Penelitian ini bertujuan untuk menganalisis keuntungan usahatani sayuran selada organik hidroponik sistem DFT (Deep Flow Technique) di lahan pekarangan, titik impas usahatani hidroponik, dan R/C ratio usahatani sayuran selada hidroponik. Penelitian ini dilaksanakan pada bulan Maret hingga April 2019 di pekarangan kantor Instalasi Penelitian dan Pengkajian Teknologi Pertanian (IP2TP) Sidondo yang berlokasi di Desa Sidondo III, Kecamatan Sigi Biromaru, Kabupaten Sigi, Provinsi Sulawesi Tengah. Penelitian ini menggunakan analisis biaya dan pendapatan, break even point, dan R/C ratio. Hasil penelitian melalui analisis titik impas atau analisis Break Even Point(BEP) yang dilihat dari dua sisi yaitu dari segi jumlah produksi/BEP (Q) dan dari segi harga jual/BEP (Rp), maka diperoleh DFT BEP (Q) sebesar 32,5 kg dan BEP (Rp) sebesar Rp 18.581,-. Hasil Analisis R/C ratio pada usahatani memperoleh angka 2,15. Usahatani sayuran selada organik hidroponik di lahan pekarangan menguntungkan.
\end{abstract}

Kata kunci: Break Even Point, DFT (Deep Flow Technique), Hidroponik, Pendapatan, R/C Ratio dan Selada

\begin{abstract}
The increase of population caused many agricultural land converted into settlements, so the challenge of fulfilling food from the agricultural sector is increasing. One of the efforts to optimize the fulfillment of food needs from increasingly narrow land is to use the plots of land with hydroponic system plantations. This study is aimed to analyze the advantages of hydroponic organic lettuce in the DFT (Deep Flow Technique) system in the plots, break-even points of hydroponic farming, and $R / C$ ratio of hydroponic vegetable farming. This research was carried out in March to April 2019. in the yard of the Sidondo Agricultural Technology Research and Assessment (IP2TP) office located in Sidondo III Village, Sigi Biromaru District, Sigi Regency, Central Sulawesi Province. This research using cost and income analysis, break even point, and $R$ $/ C$ ratio. The results of the study through break-even analysis or Break Even Point (BEP) analysis viewed from two sides: in terms of total production / BEP $(Q)$ and in terms of selling price / BEP (Rp), a DFT BEP (Q) of 32.5 is obtained $\mathrm{kg}$ and Rp. 18,581 on BEP. It's obtained 2.15 on $R / C$ Ratio Analysis in farming. Hydroponic farming in the backyard is profitable.
\end{abstract}

Keywords: Break Even Point, DFT (Deep Flow Technique), Hydroponics, Income, R / C Ratio and lettuce 


\section{PENDAHULUAN}

Jumlah penduduk yang terus mengalami peningkatan menyebabkan kebutuhan bahan pangan semakin bertambah. Pemenuhan kebutuhan pangan tersebut banyak menemui permasalahan, di antaranya adalah fenomena perubahan iklim global yang berpengaruh pada tingkat produksi dan distribusi bahan pangan, penyempitan lahan pertanian akibat penggunaan di bidang non pertanian, dan tingginya tingkat degradasi lahan sehingga menyebabkan berkurangnya hasil panen. Strategi baru dalam pemenuhan bahan pangan, diantaranya melalui pemanfaatan lahan pekarangan, perlu dikembangkan. Budidaya tanaman sistem hidroponik merupakan salah satu solusi pemenuhan kebutuhan pangan dari pekarangan, terutama dari lahan pekarangan yang sempit dengan kondisi tanah yang tidak subur dan berbatu. Hidroponik merupakan suatu metode bercocok tanam dengan menggunakan media air yang ditambahkan nutrisi (Suryani, 2015).

Kelebihan dari pertanaman sistem hidroponik, yaitu: (1) Keberhasilan tanaman untuk tumbuh dan berproduksi lebih terjamin, (2) Perawatan lebih praktis dan gangguan hama lebih terkontrol, (3) Pemakaian pupuk lebih hemat (efisien), (4) Tanaman yang mati lebih mudah diganti dengan tanaman yang baru, (5) Tidak membutuhkan banyak tenaga kasar karena metode kerja lebih hemat dan memiliki standarisasi, (6) Tanaman dapat tumbuh lebih pesat dan dengan keadaan yang tidak kotor dan rusak, (7) Hasil produksi lebih kontinyu dan lebih tinggi dibanding dengan penanaman di tanah, (8) Harga jual hidroponik lebih tinggi dari produk nonhidroponik, (9) Beberapa jenis tanaman dapat dibudidayakan di luar musim, (10) Tidak ada resiko kebanjiran, erosi, kekeringan, atau ketergantungan dengan kondisi alam, dan (11) Tanaman hidroponik dapat dilakukan pada lahan atau ruang yang terbatas, misalnya di atap, dapur atau garasi (Roidah, 2014).

Terdapat beberapa model tanam hidroponik, akan tetapi model tanam yang sering digunakan yaitu Nutrient Film Technique (NFT) dan Deep Flow Technique (DFT). Teknik NFT merupakan cara yang paling populer dalam istilah hidroponik, biasanya teknik ini diterapkan untuk skala bisnis. Kelemahan dari sistem ini adalah air nutrisi pada pada hidroponik harus terus mengalir tanpa putus, artinya jika terjadi kerusakan pompa, pemadaman listrik, atau ada masalah lain hingga sirkulasi air 
nutrisi terhenti, maka akan berisiko kematian atau mempengaruhi mutu pertumbuhan terhadap tanaman. Sedangkan teknik DFT sering digunakan pada pemanfaatan pekarangan atau pada lahan sempit. DFT merupakan metode budidaya tanaman hidroponik dengan meletakkan akar tanaman pada lapisan air dengan kedalaman 4-6 cm. Salah satu kelebihan teknik ini adalah meskipun aliran listrik padam, larutan nutrisi tetap tersedia untuk tanaman karena larutan dapat mencapai $6 \mathrm{~cm}$ (Satiti et all 2017).

Berbagai kelebihan teknologi hidroponik dan meningkatnya kebutuhan masyarakat akan komoditi sayuran organik salah satunya komoditi selada, maka terdapat peluang usaha yang menjanjikan di bidang pertanian, khususnya pada sistem hidroponik. Pengembangan usaha hidroponik dapat dilakukan dengan skala kecil untuk pemanfaatan pekarangan dan skala besar atau komersial untuk bisnis sayuran selada organik (Nazaruddin, 1998). Pengembangan usahatani sayuran selada organik di lingkup pemanfaatan pekarangan dapat menggunakan sistem hidroponik DFT. Metode ini lebih murah (hubungannya dengan penggunaan listrik) dan praktis untuk diterapkan di tingkat rumah tangga dengan produksinya yang sangat stabil dan serangan hama tanaman dapat diminimalir.

Berdasarkan hasil penelitian Fitri et all (2018), petani yang belum mampu mengalokasikan secara optimal semua faktor produksi yang ada dalam proses produksi usahataninya akan berpengaruh terhadap biaya produksi dan pendapatan petani. Pendapatan yang diperoleh petani akan berbeda-beda sesuai dengan tingkat kemampuan petani dalam mengalokasikan faktor-faktor yang dimilikinya. Dengan demikian perlu dilakukan penelitian bagaimana keuntungan usahatani sayuran selada organik sistem DFT di lahan pekarangan, titik impas usahatani sayuran selada organik, dan Revenue/Cost Ratio usahatani sayuran selada organik.

\section{METODE PENELITIAN}

Penelitian ini dilaksanakan pada bulan Maret hingga April 2019. Bertempat di pekarangan kantor Instalasi Penelitian dan Pengkajian Teknologi Pertanian (IP2TP) Sidondo yang berlokasi di Desa Sidondo III, Kecamatan Sigi Biromaru, Kabupaten Sigi, Provinsi Sulawesi Tengah. Metode hidroponik yang dilakukan adalah DFT dengan tanaman sayuran selada. 


\section{Biaya Produksi Usahatani}

Biaya adalah seluruh korbanan yang digunakan untuk menghasilkan produksi yang terdiri atas biaya tetap (Fixed Cost) (sewa lahan, biaya penyusutan, perbaikan alat-alat, bunga bank, biaya mesin), dan biaya tidak tetap (Variable Cost) (benih, pestisida, pupuk organik, pupuk kimia,tenaga kerja luar) (Fitri et all 2018). Untuk mengetahui seluruh biaya yang dibutuhkan, dapat digunakan perhitungan sebagai berikut:

$\mathrm{TC}=\mathrm{FC}+\mathrm{VC}$

Keterangan:

$\mathrm{TC}=$ Total Biaya $($ Total Cost $)$

FC = Biaya Tetap (Fixed Cost $)$

$\mathrm{VC}=$ Biaya Tidak Tetap (Variable Cost $)$

\section{Penerimaan usahatani}

Penerimaan (revenue) usahatani adalah semua nilai produk yang dihasilkan dari suatu usahatani dalam satu periode tertentu, satu musim tanam atau dalam satu tahun kegiatan usahatani. Menurut (Suratiyah, 2009), penerimaan usahatani selada hidroponik merupakan nilai yang diterima dari penjualan produk, yaitu hasil kali jumlah produksi selada hidroponik tersebut. Perhitungan penerimaan dapat dirumuskan sebagai berikut:

$\mathrm{TR}=\mathrm{P} \times \mathrm{Q}$
Keterangan:

$\mathrm{TR}=$ Total penerimaan usaha (Total Revenue)

$\mathrm{P} \quad$ = Harga jual (Price)

Q = Jumlah Produksi (Quantity)

\section{Keuntungan usahatani}

Analisis keuntungan dalam suatu usaha merupakan hasil dari pengurangan biaya produksi terhadap penerimaan yang diterima (Ibrahim, 2003). Dalam menghitung keuntungan dapat digunakan perhitungan sebagai berikut:

$\pi=\mathrm{TR}-\mathrm{TC}$

Keterangan:

$\pi \quad=$ Keuntungan (Profit)

$\mathrm{TR}=$ Total Penerimaan (Total Revenue)

$\mathrm{TC}=$ Total biaya yang dikeluarkan

(Total Cost)

\section{Analisis Break Even Point}

Analisis break even point dilakukan untuk mengetahui berapa jumlah minimum selada hidroponik yang harus terjual agar hasil penjualan yang diperoleh sama dengan jumlah biaya yang dikeluarkan, serta untuk mengetahui berapa jumlah penerimaan minimal petani agar usahanya tidak untung maupun tidak rugi (Manulang, 2005). Pendekatan untuk perhitungan titik impas dalam usaha sayuran hidroponik ini 
adalah BEP dalam jumlah unit produksi (Kg) dan dalam bentuk rupiah (Rp). Perhitungan titik impas dapat dilakukan dengan menggunakan rumus sebagai berikut:

\section{Perhitungan BEP atas dasar unit}

$B E P(Q)=\frac{F C}{P-V}$

Keterangan:

FC = Total Biaya Tetap (Fix Cost)

$\mathrm{P} \quad=$ Harga jual/Unit (Price)

$\mathrm{V}=$ Biaya variable per $\mathrm{Kg}$

Q = Jumlah Unit/ Kuantitas Produksi

Perhitungan BEP atas dasar penjualan dalam rupiah

$B E P(Q)=\frac{F C}{1-\frac{V C}{S}}$

Keterangan:

$\mathrm{FC}=$ Total Biaya Tetap (Fixed Cost)

$\mathrm{VC}=$ Total Biaya Tidak Tetap (Variable Cost)

$\mathrm{S} \quad=$ Jumlah Penjualan (Sales)

\section{Rasio Revenue-Cost}

Analisis rasio penerimaan dan biaya ( $\mathrm{R} / \mathrm{C}$ ratio) digunakan untuk mengetahui seberapa jauh setiap nilai rupiah biaya yang dikeluarkan dapat memberikan sejumlah nilai penerimaan sebagai manfaatnya (Suratiyah, 2009). Rumus yang digunakan dalam perhitungan $\mathrm{R} / \mathrm{C}$ ratio adalah sebagai berikut:

$R / C($ ratio $)=\frac{T R}{T C}$

Keterangan:

$\mathrm{R} / \mathrm{C}$ Ratio $=$ Rasio perbandingan antara penerimaan dengan biaya

TR $=$ Total Penerimaan (Total Revenue)

TC $=$ Total Biaya (Total Cost)

Tujuan menganalisis nilai $\mathrm{R} / \mathrm{C}$ ratio untuk melihat kelayakan suatu usaha. Semakin besar nilai $\mathrm{R} / \mathrm{C}$ rasio maka usaha tersebut semakin efisien.

- $\mathrm{R} / \mathrm{C}$ Ratio > 1 maka usaha menguntungkan dan layak untuk diusahakan.

- $\mathrm{R} / \mathrm{C}$ Ratio = 1 maka usaha tidak menguntungkan dn tidak juga merugikan.

- $\mathrm{R} / \mathrm{C}$ Ratio $<1$ maka usaha mengalami kerugian dan tidak layak di diusahakan.

\section{Definisi Operasional}

Konsep yang telah dikemukakan, maka secara operasional diberikan penjelasan sebagai berikut:

1. Produksi sayuran hidroponik ialah jumlah output atau hasil panen sayuran hidroponik dari luas lahan selama satu kali musim tanam.

2. Biaya produksi ialah seluruh biaya 
yang dikeluarkan dalam kegiatan usahatani sayuran hidroponik dalam satu kali musim tanam yang terdiri atas biaya tetap dan biaya variabel.

3. Biaya total ialah total dari biaya tetap dan biaya variabel.

4. Biaya tetap ialah biaya yang harus dikeluarkan dalam berusahatani yang besar kecilnya tidak tergantung pada volume produksi.

5. Biaya variabel ialah biaya yang besar kecilnya akan berpengaruh secara langsung dengan jumlah produksi.

6. Harga input ialah harga input faktorfaktor produksi, seperti sarana produksi dan peralatan pertanian yang harus dibayar oleh petani.

7. Harga produk ialah nilai tukar produk dalam satu kali musim tanam.

8. Penerimaan ialah uang yang diterima dari jumlah produksi yang dihasilkan untuk satu kali musim tanam dikalikan dengan harga produk per $\mathrm{kg}$ di tingkat petani.

9. Keuntungan ialah penerimaan usahatani dikurangi dengan biaya total (biaya tetap dan biaya variabel) yang dikeluarkan selama proses produksi dalam satu kali tanam.

10. Luas greenhouse ialah luas areal usahatani sayuran hidroponik yang digunakan dalam berusahatani.
11. Nutrisi ialah banyaknya unsur hara yang digunakan dalam usahatani sayuran hidroponik.

12. Tenaga kerja ialah banyaknya tenaga kerja yang tercurahkan dalam proses produksi sampai panen dalam satu kali musim tanam.

\section{HASIL DAN PEMBAHASAN}

\section{Metode Hidroponik}

Metode hidroponik yang dikembangkan di lokasi pemanfaatan pekarangan dalam pengembangan usahatani sayuran hidroponik menggunakan metode DFT karena sistem tidak tergantung pada ketersediaan listrik selama 24 jam, media tanam yang digunakan mudah diaplikasikan dan instalasi tanaman dapat digunakan pada lahan yang sempit. Selain itu, metode DFT ini bahan-bahannya mudah didapatkan, murah, dan praktis. Proses pemeliharaanya atau pembersihannya juga sangat mudah sehingga serangan hama penyakit bisa diatasi dan dapat meningkatkan produksi usahatani sayuran hidroponik (Roidah, 2014). Prinsip dasar bertanam secara hidroponik DFT adalah dengan meletakkan akar tanaman pada lapisan air dengan kedalaman 4-6 cm.

Kelebihan dari metode ini adalah tanaman akan mendapatkan pasokan air 
dan juga nutrisi secara rutin, sehingga bisa memudahkan pensuplaian nutrisi pada tanaman. Media tanam yang digunakan yaitu rockwoll. Rongga udara pada rockwoll harus terisi oleh air. Rockwoll yang jenuh air adalah keadaan yang terbaik, agar benih/biji mudah berkecambah. Untuk persemaian memerlukan tray plastik dan rockwoll yang sudah jenuh air dan berukuran $2,5 \mathrm{x}$ $2,5 \times 2,5 \mathrm{~cm}$. Nutrisi yang digunakan merupakan nutrisi pabrikan yang terdiri atas unsur hara makro dan mikro yang dibutuhkan tanaman. Satu greenhouse membutuhkan 3 liter nutrisi yang sudah dicampurkan dengan 855 liter air untuk 1 kali produksi. Perawatan yang dilakukan yaitu pengecekan kandungan nutrisi dalam bak penampung air dan pembersihan bak penampung air untuk menghindari bakteri yang dapat mengganggu tanaman sayuran hidroponik serta melakukan seleksi tanaman yang terkontaminasi oleh penyakit agar tidak menular ke tanaman yang lain.

\section{Biaya Produksi Selada Hidroponik}

Biaya produksi adalah biaya yang dikeluarkan untuk proses produksi usahanya yang dimulai sejak persemaian sampai pada saat siap untuk dijual. Biaya produksi meliputi biaya tetap (Fixed
Cost) dan biaya tidak tetap (Variable Cost). Biaya tetap adalah biaya yang dikeluarkan tanpa dipengaruhi besar atau kecilnya produksi. Berdasarkan Tabel 1 biaya tetap yang dikeluarkan pada usahatani selada dengan sistem hidroponik DFT adalah sebesar R. 400.676,-- Biaya tidak tetap atau biaya variabel adalah biaya yang dikeluarkan tergantung dari besar atau kecilnya produksi. Biaya tidak tetap pada usahatani selada sistem hidroponik DFT adalah sebesar Rp 900.000,- dengan produksi selada sebanyak $70 \mathrm{~kg}$ per 500 lubang pada media tanam.

Total biaya adalah seluruh biaya yang dikeluarkan dalam proses usahatani tersebut. Biaya usahatani terdiri atas biaya tetap dan biaya tidak tetap. Total biaya tetap usahatani selada hidroponik sebesar Rp 1.300.676. Total biaya yang dikeluarkan oleh usahatani selada sistem hidroponik pada Tabel 1.

Tabel 1. Total Biaya Tetap Usahatani Selada Hidroponik

\begin{tabular}{cccc}
\hline No & $\begin{array}{c}\text { Biaya } \\
\text { Tetap (Rp) }\end{array}$ & $\begin{array}{c}\text { Biaya Tidak } \\
\text { Tetap (Rp) }\end{array}$ & $\begin{array}{c}\text { Total Biaya } \\
(\mathbf{R p})\end{array}$ \\
\hline 1 & 400.676 & 900.000 & 1.300 .676 \\
\hline Sumber: Data Primer Setelah Diolah, 2019
\end{tabular}

\section{Penerimaan Usahatani Selada \\ Hidroponik}

Penelitian ini menggunakan data pada satu periode tanam yaitu bulan 
Maret-April 2019. Penerimaan usahatani selada hidroponik dihitung dengan mengalikan jumlah produksi selada dengan harga selada/kg. Produksi selada bulan Maret 2019 adalah $70 \mathrm{~kg}$ selada untuk 500 lubang pada media tanam. Dalam satu kilonya terdapat 7-8 pokok selada dimana per-kilonya dijual dengan harga Rp 40.000/kg, sehingga bila dikonversikan akan mendapat total penerimaan sebesar Rp 2.800.000.

\section{Keuntungan Usahatani}

Keuntungan selada merupakan selisih antara penerimaan yang didapatkan di kurang dengan total biaya yang sudah dikeluarkan pada proses usahatani selada dengan sistem hidroponik (Tabel 2).

Tabel 2. Keuntungan Usahatani Selada

\begin{tabular}{clr}
\multicolumn{3}{c}{ Hidroponik } \\
\hline No & \multicolumn{1}{c}{ Uraian } & Jumlah \\
\hline 1 & Produksi (kg) & 70 \\
2 & Harga (Rp) & 40.000 \\
3 & Penerimaan (Rp) & 2.800 .000 \\
4 & Biaya (Rp) & 1.300 .676 \\
5 & Keuntungan (Rp) & 1.499 .324 \\
\hline \multicolumn{2}{l}{ Sumber: Data Primer Setelah Diolah, 2019}
\end{tabular}

Berdasarkan Tabel 2 hasil penelitian pada usahatani selada, sistem penerimaannya diperoleh dari jumlah produksi dikalikan dengan harga jual, yaitu 70 kg dikalikan Rp 40.000,sehingga penerimaan diperoleh penerimaan sebesar Rp 2.800.000,-
Sedang untuk mengetahui pendapatan maka penerimaan dikurang dengan total biaya yang sudah dikeluarkan yaitu sebesar Rp 1.300.676,- $\quad$ sehingga diperoleh keuntungan sebesar Rp 1.499.324,-

\section{Analisis Break Even Point Usahatani}

\section{Selada Hidroponik}

Analisis Break Even Point dilakukan untuk mengetahui berapa jumlah minimum tanaman selada yang harus terjual agar hasil penjualan yang diperoleh sama dengan jumlah biaya yang dikeluarkan serta untuk mengetahui berapa jumlah penerimaan minimal petani agar usahanya tidak untung maupun tidak rugi. Dalam perhitungan titik impas (BEP), biaya variabel dan biaya tetap yang dikeluarkan harus dipisahkan secara jelas. Pendekatan untuk perhitungan titik impas dalam usaha sayuran hidroponik adalah BEP dalam jumlah unit produksi $(\mathrm{Kg})$ dan dalam bentuk rupiah $(\mathrm{Rp})$. Dalam perhitungan usahatani selada sistem DFT diperoleh BEP (Q) adalah sebesar 32,5 kg dan BEP (Rp) sebesar Rp 18.581,-. Sehingga apabila jumlah penjualan (Q) selada berada pada jumlah tersebut maka usaha berada pada titik impas atau tidak mengalami laba ataupun kerugian; begitu 
juga dengan BEP Harga (Rp) yang dibebankan pada setiap produk. Apabila pedagang menjualnya pada kisaran harga tersebut maka usaha juga akan berada pada titik impas.

\section{Analisis R/C Ratio Usahatani Selada pada Sistem Hidroponik}

Perhitungan R/C Ratio adalah untuk mengetahui perbandingan antara penerimaan dengan biaya yang dikeluarkan. Jika nilai $\mathrm{R} / \mathrm{C}$ ratio lebih kecil dari 1, maka usaha tidak menguntungkan dan tidak layak untuk diusahakan. Apabila nilainya sama dengan 1, maka usahatani tersebut tidak menguntungkan dan tidak pula rugi. Sedangkan apabila lebih besar dari pada 1 maka usahatani menguntungkan dan layak diusahakan. Berdasarkan hasil perhitungan diketahui bahwa $\mathrm{R} / \mathrm{C}$ ratio sebesar 2,15. R/C ratio yang diperoleh usaha ini termasuk ke dalam usaha yang menguntungkan, artinya setiap Rp 1 yang diusahakan sebagai modal usahatani akan diperoleh hasil sebesar Rp 2,15 dan usaha ini layak untuk diusahakan.

\section{KESIMPULAN DAN SARAN}

\section{Kesimpulan}

Berdasarkan hasil pemaparan maka dapat disimpulkan keuntungan yang diperoleh pada usahatani selada hidroponik dengan sistem DFT sebesar Rp 1.499.324/bulan. Analisis titik impas atau Analisis Break Even Point dapat dilihat dari 2 sisi yaitu dari segi jumlah produksi/BEP (Q) dan dari segi harga jual/BEP (Rp). Untuk usahatani selada hidroponik sistem DFT BEP (Q) sebesar 22,5 $\mathrm{kg}$ dan BEP (RP) sebesar Rp 12.587,-.. Artinya apabila usahatani selada memproduksi selada dengan biaya produksi yang sama dan hasil produksi $22,5 \mathrm{~kg}$ dan harga jualnya Rp 12.587,-, maka usahatani selada hidroponik tersebut berada pada keadaan titik impas, dimana usahatani tidak mendapatkan laba namun tidak juga mengalami kerugian. Analisis R/C Ratio pada usahatani memperoleh angka 2,15, berarti usaha tersebut layak untuk diusahakan. Setiap tambahan modal Rp 1 maka usaha tersebut akan memperoleh hasil produksi senilai Rp 2,15.

\section{Saran}

Petani perlu melakukan pencegahan atau penanggulangan hama sejak dini dengan menggunakan pestisida nabati agar tanaman sayur dapat aman dikonsumsi.

\section{DAFTAR PUSTAKA}

Fitri, A., Harianto, H., \& Asmarantaka, R. W. (2018). Analisis Pendapatan 
Usahatani Sawi Pola Kemitraan dan Non Mitra di Kecamatan Megamendung Kabupaten Bogor Jawa Barat. Journal of Food System \& Agribusiness, 2(2), 94-99. https://doi.org/10.25181/jofsa.v2i2. 1115

Ibrahim, Y. (2003). Studi Kelayakan Bisnis. Jakarta (ID): Roneka Sipta.

Manulang. (2005). Pengantar Manajemen Keuangan. Yogyakarta (ID): Andi.

Nazaruddin. (1998). Budidaya dan Pengaturan Panen Sayuran Dataran Rendah. Jakarta (ID): Penebar Swadaya.
Retno Suryani. (2015). Hidroponik. Yogyakarta (ID): ArCitra.

Roidah, I. S. (2014). Pemanfaatan Lahan Dengan Menggunakan Sistem Hidroponik. Jurnal Universitas Tulungagung BONOROWO Tahun, 1(2), 43-50. Retrieved from file:///C:/Users/ASUS/Downloads/1 4-22-1-SM.pdf

Satiti, R., Lestari, D. A. H., \& Suryani, A. (2017). Sistem Agribisnis dan Kemitraan Usaha Penggemukan Sapi Potong di Koperasi Gunung Madu. Jurnal Ilmu-Ilmu Agribisnis, 5(4), 352-359.

Suratiyah K. (2009). Ilmu Usahatani. Jakarta (ID): PT Penebar Swadaya. 